\title{
Evidence-based cognitive rehabilitation after acquired brain injury: A systematic review of content of treatment
}

Citation for published version (APA):

van Heugten, C. M., Gregorio, G. W., \& Wade, D. (2012). Evidence-based cognitive rehabilitation after acquired brain injury: A systematic review of content of treatment. Neuropsychological Rehabilitation, 22(5), 653-673. https://doi.org/10.1080/09602011.2012.680891

Document status and date:

Published: 01/01/2012

DOI:

10.1080/09602011.2012.680891

Document Version:

Publisher's PDF, also known as Version of record

Document license:

Taverne

Please check the document version of this publication:

- A submitted manuscript is the version of the article upon submission and before peer-review. There can be important differences between the submitted version and the official published version of record.

People interested in the research are advised to contact the author for the final version of the publication, or visit the DOI to the publisher's website.

- The final author version and the galley proof are versions of the publication after peer review.

- The final published version features the final layout of the paper including the volume, issue and page numbers.

Link to publication

\footnotetext{
General rights rights.

- You may freely distribute the URL identifying the publication in the public portal. please follow below link for the End User Agreement:

www.umlib.nl/taverne-license

Take down policy

If you believe that this document breaches copyright please contact us at:

repository@maastrichtuniversity.nl

providing details and we will investigate your claim.
}

Copyright and moral rights for the publications made accessible in the public portal are retained by the authors and/or other copyright owners and it is a condition of accessing publications that users recognise and abide by the legal requirements associated with these

- Users may download and print one copy of any publication from the public portal for the purpose of private study or research.

- You may not further distribute the material or use it for any profit-making activity or commercial gain

If the publication is distributed under the terms of Article $25 \mathrm{fa}$ of the Dutch Copyright Act, indicated by the "Taverne" license above, 


\section{Neuropsychological Rehabilitation}

\section{Evidence-based cognitive rehabilitation after acquired brain injury: A systematic review of content of treatment}

\section{Caroline van Heugten , Gisela Wolters Gregório \& Derick Wade}

To cite this article: Caroline van Heugten , Gisela Wolters Gregório \& Derick Wade (2012)

Evidence-based cognitive rehabilitation after acquired brain injury: A systematic review of content of treatment, Neuropsychological Rehabilitation, 22:5, 653-673, DOI: 10.1080/09602011.2012.680891

To link to this article: https://doi.org/10.1080/09602011.2012.680891

曲 Published online: 27 Apr 2012.

6 Submit your article to this journal $\widetilde{ }$

III Article views: 4943

Q View related articles $₫$

Citing articles: 17 View citing articles 


\title{
Evidence-based cognitive rehabilitation after acquired brain injury: A systematic review of content of treatment
}

\author{
Caroline van Heugten ${ }^{1,2}$, Gisela Wolters Gregório ${ }^{1}$, and \\ Derick Wade ${ }^{3,4}$ \\ ${ }^{1}$ School for Mental Health and Neuroscience, University of Maastricht, \\ Maastricht, The Netherlands \\ ${ }^{2}$ Department of Neuropsychology and Psychopharmacology, University of \\ Maastricht, Maastricht, The Netherlands \\ ${ }^{3}$ Care and Public Health Research Institute, University of Maastricht, \\ Maastricht, The Netherlands \\ ${ }^{4}$ Oxford Centre for Enablement, Oxford, United Kingdom
}

\begin{abstract}
We reviewed all randomised trials on cognitive rehabilitation in order to determine the effective elements in terms of patients' and treatment characteristics, treatment goals and outcome. A total of 95 random controlled trials were included from January 1980 until August 2010 studying 4068 patients in total. Most studies had been conducted on language $(n=25)$, visuospatial functioning $(n=24)$, and memory $(n=14)$. Stroke patients were the commonest subjects $(57 \%$; overall mean age $=52.2, S D=15.0$ years). Of the interventions $39 \%$ were offered more than 12 months after onset and $23 \%$ were offered within two months of onset. The mean $(S D)$ number of hours of treatment actually delivered was 4.1 (3.6) per week; treatment was mostly offered individually. No papers gave specific information on the expertise or competences of the staff involved. With 95 RCTs there is a large body of evidence to support the efficacy of cognitive rehabilitation, and the current study can serve as a database for clinicians and researchers. But most studies have given little information about the actual content of the treatment which makes it difficult to use the studies when making treatment decisions in daily
\end{abstract}

Correspondence should be addressed to Caroline van Heugten, Department of Psychiatry and Neuropsychology, Maastricht University, PO Box 616, 6200 MD Maastricht, The Netherlands. E-mail:c.vanheugten@maastrichtuniversity.nl

(C) 2012 Psychology Press, an imprint of the Taylor \& Francis Group, an Informa business http://www.psypress.com/neurorehab http://dx.doi.org/10.1080/09602011.2012.680891 
clinical practice. We suggest developing an international checklist to make standardised description of non-pharmacological complex interventions possible.

Keywords: Brain injuries; Stroke; Cognition disorders; Rehabilitation; Randomised controlled trial.

\section{INTRODUCTION}

Impairments of cognitive function are frequent after acquired brain injury and cause problems in activities of daily life and participation in society. Cognitive rehabilitation is the treatment of choice for these deficits and can be defined as "a systematic, functionally oriented service of therapeutic activities that is based on assessment and understanding the patients' brain-behavioral deficits" (Cicerone et al., 2000, pp. 1596-1597). Rehabilitation of cognitive deficits is recognised as a standard component of rehabilitation programmes for patients with acquired brain injury as can be seen in many national clinical guidelines (i.e., American Heart Association, UK Royal College of Physicians).

The Brain Injury Interdisciplinary Special Interest Group (BI-ISIG) of the American Congress of Rehabilitation Medicine (ACRM) previously conducted a systematic review of the literature up to 2008 on cognitive rehabilitation for people with traumatic brain injury (TBI) or stroke (Cicerone et al., $2000,2005,2011)$. The review found that there was a differential benefit in favour of cognitive rehabilitation in almost $80 \%$ of all treatment comparisons. Recommendations for clinical practice were formulated accordingly. In addition, Rohling, Faust, Beverly, and Demarkis (2009) performed a metaanalytic re-examination of Cicerone et al.'s (2000, 2005) reviews to provide treatment effect sizes and showed that there is sufficient evidence for the effectiveness of attention training after traumatic brain injury, and the effectiveness of language and visuo-spatial training for aphasia and neglect syndromes after stroke.

However, when a healthcare professional wants to apply evidence from a study in everyday clinical practice, or when a researcher wishes to replicate the study, the details listed below are needed to allow practical use of the information generated by research studies:

- What were the clinical characteristics of the patients in the study?

- What was the treatment studied (content, process, resources, etc.)?

- What was the treatment setting?

- What are the costs/benefits for this patient (on the basis of the prognosis and condition of the patient)? 
In practice this information is not easily found in the published literature, either in reviews or in the original papers. We therefore set out to review systematically what detailed information is available about the cognitive rehabilitation interventions that have been evaluated. As a necessary part of this, we also had to establish how many randomised controlled trials evaluating interventions designed to ameliorate cognitive impairments are now published.

\section{METHODS}

A systematic literature search was performed to identify randomised controlled studies evaluating interventions targeted at people with cognitive deficits associated with acquired brain injuries, using PubMed and PsycINFO which are the primary electronic databases covering this area of research. We searched the period from January 1980 until August 2010. Details of the search strategy are presented in Table 1 and are available from the corresponding author. The starting point for the search strategy was the one by the BI-ISIG to make sure the same 46 class I studies identified by Cicerone et al. $(2000,2005)$ would be identified. In addition, we hand-searched the reference lists of the reviewed articles, and of relevant systematic reviews from the Cochrane database (i.e., reviews on memory, neglect, aphasia, apraxia, and attention). The second author performed the literature search as well as the primary selection of articles based on the title and abstracts.

\section{Study selection}

Figure 1 shows the selection of papers. Studies were included only when they addressed the effect of cognitive rehabilitation in an RCT related to non-

TABLE 1

Search terms

\begin{tabular}{cc}
\hline Cognitive domains & $\begin{array}{c}\text { Attention/concentration, information processing/ slowness, awareness/ } \\
\text { insight, cognition, communication, executive/ planning/organisation/ } \\
\text { regulation, language/aphasia, memory, perception/perceptual/agnosia/ } \\
\text { neglect/visual, problem solving, reasoning, apraxia/dyspraxia } \\
\text { Rehabilitation } \\
\text { Rehabilitation, remediation, education, training, retraining, paging system, } \\
\text { treatment, treatments, therapy } \\
\text { Acquired brain } \\
\text { injury }\end{array} \quad \begin{array}{l}\text { Stroke, brain injuries/brain-injuries/brain injury/brain-injury/brain injured/ } \\
\text { brain-injured, head injuries/head-injuries/head injury/head-injury/head } \\
\text { injured/head-injured, brain damage/brain damaged, tbi/head trauma/ } \\
\text { traumatic, cerebrovascular disorders/cerebrovascular accident/ } \\
\text { cerebrovascular accidents/cva/stroke/poststroke/post-stroke/post stroke, } \\
\text { chronic aphasia }\end{array}$ \\
\hline
\end{tabular}




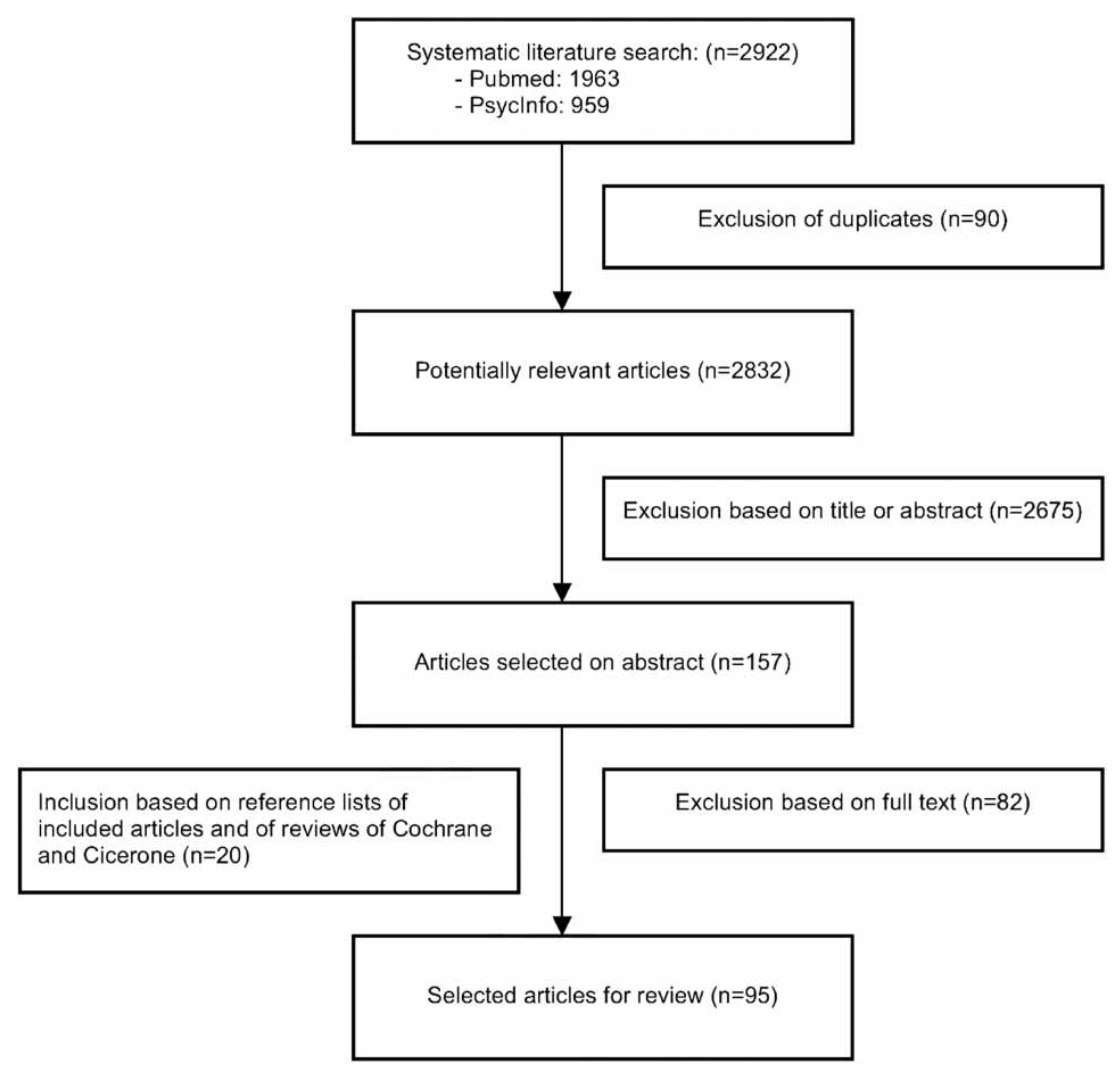

Figure 1. Flow-chart.

progressive acquired brain injury, defined operationally in the search terms. Quasi or semi-randomised trials, controlled comparative studies or uncontrolled cohort studies were excluded. This process yielded 959 published articles in PsycINFO and 1963 in PubMed.

The abstracts were reviewed to eliminate reports according to seven exclusion criteria: (1) no intervention; (2) design other than RCT; (3) reports that did not explicitly describe randomisation of patients (i.e., randomised was used in the title but the procedure was not described in the paper itself); (4) subjects other than persons with acquired brain injury; (5) pharmacological interventions; (6) interventions not aimed at cognitive deficits; and (7) nonEnglish language papers. Through this screening process, 157 articles were selected for inclusion in the study. After reviewing the complete reports enabling us to check all criteria, 95 articles were finally included in the review. 
These articles were then assigned to categories according to their primary area of intervention as was done in the previous reviews (Cicerone et al., 2000; 2005): awareness, visuospatial functioning, memory, attention, executive functioning, apraxia, language and communication, and multi-domain studies (i.e., targeting more than one cognitive domain, such as memory and attention). Studies investigating comprehensive-holistic cognitive rehabilitation programmes aimed at community reintegration were not included, because a recent systematic review of these programmes described patient and treatment characteristics extensively (Geurtsen, van Heugten, Martina, \& Geurts, 2010).

\section{Description of treatment given}

Each paper included was specifically reviewed to discover details on the treatment given. Three sources were used. First, the original paper itself; any description given was reviewed and data were extracted. Second, if the report gave a reference to a paper or publically available manual or document, the document was reviewed and data on treatment were extracted. Third, a brief search of the same databases was made using the name of the first author only (but accepting the name in any position in identified papers), restricting the search to four years before and after the publication of the main study. The titles and abstracts were read to determine whether the paper described the treatment investigated, and if so data on treatment were extracted.

\section{Data extraction}

The patient and treatment characteristics that we felt should be available were formulated by the authors on the basis of clinical experience, available guidelines for description of treatments (for instance, Netherlands Association for Medical Rehabilitation), and consensus. These variables were then discussed with the national committee on cognitive rehabilitation in The Netherlands (consisting of rehabilitation physicians and psychologists) and the final set of variables was determined on the basis of consensus. The first and the second author reviewed the articles separately after selection and independently extracted the following data: (1) patient characteristics (number of patients, age, type of injury, time since injury); (2) treatment characteristics (treatment setting; duration and intensity of treatment; type of treatment, group and/or individual versus direct therapy or applied in daily life; discipline(s) of the therapists involved; involvement of the caregiver in treatment); and (3) treatment goals and outcome. Any disagreements were resolved by discussion until consensus was reached. Disagreements were mainly caused by incomplete description of characteristics in the literature. 


\section{RESULTS}

Ninety-five RCTs were selected (described in 96 papers; references Dirette and Hinojosa [1999] and Dirette, Hinojosa, and Carnevale [1999] describe the same study), published up to August 2010. The frequency of studies per domain (including all references) is shown in Table 2. Most studies were conducted in the area of language and communication $(n=25)$, visuospatial functioning $(n=24)$ and memory $(n=14)$.

\section{Patient characteristics}

In total 4068 patients were studied in the 95 studies. The mean $(S D)$ number of patients per study was 42.8 (47.0) varying from 4 to 360 . The largest study by Vanderploeg et al. (2008), for instance, compared a protocol-specific cognitive didactic approach with a functional experimental approach in a group of 360 adult veterans or active duty military service members with moderate to severe traumatic brain injury. Most studies $(n=37)$ were small with only 4 to 20 patients. Only seven studies included more than 100 patients.

The mean age of the total sample $(n=94)$ was 52.2 (SD 15.0; range 1777) years. The older age groups were mostly stroke patients as in the study of Kalra, Perez, Gupta, and Wittink (1997) in which visual neglect was treated in a group with a mean age of $77.0(8.6)$ years. Most studies $(n=56 ; 59 \%)$ selected patients aged between 20 and 60 years.

The time since brain injury was described in 87 studies and was 24.0 months on average ( $S D$ 34.0; range 5 days -82.5 months). The most acute patients were studied by Carter, Howard, and O'Neil (1983); inclusion of patients in the programme was at a mean $(S D)$ of 4.8 (1.6) days. In most of the studies $(n=37 ; 43 \%)$, however, the time since injury was more than 1 year, while in $23 \%$ the patients were included less than 2 months after onset $(n=22)$.

Stroke was the most studied diagnosis $(n=54 ; 57 \%)$; in 22 studies (23\%) patients with traumatic and closed head injuries were included. The remaining studies dealt with heterogeneous populations $(n=16)$ or other forms of brain injuries $(n=3)$ such as solvent-induced chronic toxic encephalopathy (van Hout, Wekking, Berg, \& Deelman, 2008).

Further detailed information on patient characteristics can be obtained from the authors.

\section{Intervention characteristics}

We applied the three sources for retrieval of treatment information as described in the methods section. In 40 papers the only available information was found in the paper itself. For instance, in the paper by Cheng and Man (2006) the Awareness Intervention Program (AIP) is described in the methods section, but no further information to other sources is given. In 
TABLE 2

Study domains

\begin{tabular}{|c|c|c|c|}
\hline Domain & $N$ & $\%$ & Author/year \\
\hline Awareness & 2 & 2 & $\begin{array}{l}\text { Cheng \& Man, 2006; Goverover, Johnston, Toglia, \& Deluca, } \\
2007\end{array}$ \\
\hline $\begin{array}{l}\text { Visuospatial } \\
\text { functioning }\end{array}$ & 24 & 25 & $\begin{array}{l}\text { Antonucci et al., 1995; Cherney, Halper, \& Papachronis, 2003; } \\
\text { Dirette \& Hinojosa, 1999; Dirette, et al., 1999; Edmans, } \\
\text { Webster, \& Lincoln, 2000; Fanthome, Lincoln, Drummond, } \\
\text { \& Walker, 1995; Jacquin-Courtois et al., 2010; Kalra et al., } \\
\text { 1997; Kasten et al., 1998; Katz et al., 2005; Lincoln, Whiting, } \\
\text { Cockburn, \& Bhavnani, 1985; Luukkainen-Markkula, } \\
\text { Tarkka, Pitkänen, Sivenius, \& Hämäläinen, 2009; Neistadt, } \\
\text { 1992; Poggel, Kasten, \& Sabel, 2004; Robertson, McMillan, } \\
\text { MacLeod, Edgeworth, \& Brock, 2002; Rossi, Kheyfets, \& } \\
\text { Reding, 1990; Rusconi, Meinecke, Sbrissa, \& Bernardini, } \\
\text { 2002; Si Hyun et al., 2009; Taylor, Schaeffer, Blumenthal, \& } \\
\text { Grisell, 1971; Tsang, Sze, \& Fong, 2009; Weinberg et al., } \\
\text { 1977; 1979; Weinberg, Piasetsky, Diller, \& Gordon, 1982; } \\
\text { Wiart et al., 1997; Zeloni, Farnè, \& Baccini, 2002 }\end{array}$ \\
\hline Memory & 14 & 15 & $\begin{array}{l}\text { Berg, Koning-Haanstra, \& Deelman, 1991; Doornhein \& De } \\
\text { Haan, 1998; Dou, Man, Ou, Zheng, \& Tam, 2006; Freeman, } \\
\text { Mittenberg, Dicowden, \& Bat-Ami, 1992; Hildebrandt, } \\
\text { Bussmann-Mork, \& Schwendemann, 2006; Kaschel et al., } \\
\text { 2002; Kerner \& Acker, 1985; Ownsworth \& McFarland, } \\
\text { 1999; Rose et al., 1999; Ryan \& Ruff, 1988; Schmitter- } \\
\text { Edgecombe, Fahy, Whelan, \& Long, 1995; Thickpenny- } \\
\text { Davis \& Barker-Collo, 2007; Twum \& Parente, 1994; } \\
\text { Westerberg et al., } 2007\end{array}$ \\
\hline Attention & 10 & 11 & $\begin{array}{l}\text { Barker-Collo et al., 2009; Couillet et al., 2010; Fasotti, Kovacs, } \\
\text { Eling, \& Brouwer, 2000; Gray, Robertson, Pentland, \& } \\
\text { Anderson, 1992; Malec, Jones, Rao, \& Stubbs, 1984; Mazer } \\
\text { et al., 2003; Niemann, Ruff, \& Baser, 1990; Novack, } \\
\text { Caldwell, Duke, Bergquist, \& Gage, 1996; Sohlberg et al., } \\
\text { 2000; Winkens, Van Heugten, Wade, Habets, \& Fasotti, } 2009\end{array}$ \\
\hline Executive functioning & 6 & 6 & $\begin{array}{l}\text { Hewitt et al., 2006; Levine et al., 2000; Man et al., 2006; } \\
\text { McPherson, Kayes, \& Weatherall, 2009; Soong, Tam, Man, } \\
\text { \& Hui-Chan, 2005; Spikman et al., } 2010\end{array}$ \\
\hline Apraxia & 3 & 3 & $\begin{array}{l}\text { Donkervoort, Dekker, Stehmann-Saris, \& Deelman, 2001; } \\
\text { Smania et al., 2006; Smania, Girardi, Domenicali, Lora, \& } \\
\text { Aglioti, } 2000\end{array}$ \\
\hline $\begin{array}{l}\text { Language and } \\
\text { communication }\end{array}$ & 25 & 26 & $\begin{array}{l}\text { Bakheit et al., 2007; Dahlberg et al., 2007; David, Enderby, \& } \\
\text { Bainton, 1982; Denes, Perazzolo, Piani, \& Piccione, 1996; Di } \\
\text { Carlo, 1980; Doesborgh et al., 2004a; 2004b; Drummond \& } \\
\text { Rentschler, 1981; Elman \& Bernstein-Ellis, 1999; Hinckley, } \\
\text { Patterson, \& Carr, 2001; Katz \& Wertz, 1997; Lincoln et al., } \\
\text { 1984; Lincoln \& Pickersgill, 1984; Lincoln, Pickersgill, } \\
\text { Hankey, \& Hilton, 1982; Lyon et al., 1997; MacKay, }\end{array}$ \\
\hline
\end{tabular}


TABLE 2. Continued.

\begin{tabular}{|c|c|c|c|}
\hline Domain & $N$ & $\%$ & Author/year \\
\hline & & & $\begin{array}{l}\text { Holmes, \& Gersumky, 1988; Meikle et al., 1979; Meinzer, } \\
\text { Streiftau, \& Rockstroh, 2007; Prins et al., 1989; Pulvermuller } \\
\text { et al., 2001; Rochon, Laird, Bose, \& Scofield, 2005; Shewan } \\
\text { \& Kertesz, 1984; Wertz et al., 1981; Wertz, Weiss, Aten, \& } \\
\text { Brookshire, 1986; Worrall \& Yiu, 2000 }\end{array}$ \\
\hline Multi-domain & 11 & 12 & $\begin{array}{l}\text { Carter et al., 1983; Ruff et al., 1994; Salazar et al., 2000; } \\
\text { Sarkamo et al., 2008; Soderback, 1988; Sturm \& Willmes, } \\
\text { 1991; Thomas-Stonell, Johnson, Schuller, \& Jutai, 1994; } \\
\text { Tiersky et al., 2005; van Hout et al., 2008; Vanderploeg et al., } \\
\text { 2008; Watanabe, Black, Zafonte, Millis, \& Mann, } 1998\end{array}$ \\
\hline Total & 95 & 100 & \\
\hline
\end{tabular}

Dirette and Hinojosa (1999) and Dirette, Hinojosa, and Carnevale (1999) is the same study.

studies using medical or other devices (prisms, software programs or virtual reality programs; $n=7$ ), the information should include the type of device used; in those cases further information is not necessary, for instance, type of prisms (Jacquin-Courtois et al., 2010) or a software program (Dirette, Hinojosa, \& Carnevale, 1999). In 45 papers a reference is given to another study where a specific task which is practised during treatment or elements from the treatment are described, or the complete treatment is described as it had been evaluated before. This is the case in the study by Antonucci et al. (1995) who state that the training is specified in detail elsewhere. Most of the papers however state that "the treatment was derived from" or "the treatment was based on" and going to the reference given does not lead to specific information. The same holds for references to more general methods such as "role playing" where the reference does not give sufficient information making replication or application in one's own setting possible (i.e., a handbook). In only two papers a reference to a treatment manual is given which is retrievable through open access. This concerns the Attention Process Training, evaluated in the paper by Sohlberg, McLaughlin, Pavese, Heidrich, and Posner (2000) which can be obtained. We could find only one paper where the authors mention that further information about the treatment can be requested through one of the authors (Spikman, Boelen, Lamberts, Brouwer, \& Fasotti, 2010). A summary table of the intervention characteristics can be obtained from the authors.

\section{Frequency, intensity and duration}

Information on frequency, intensity and duration of treatment is summarised in Table 3. It is obvious that this information was not always given and that 
TABLE 3

Frequency, duration and intensity of treatment

\begin{tabular}{|c|c|c|c|c|c|c|}
\hline & \multicolumn{2}{|c|}{ Total } & \multicolumn{2}{|c|}{ Planned } & \multicolumn{2}{|c|}{ Actual } \\
\hline & $n$ & $M(S D)$ & $n$ & $M(S D)$ & $n$ & $M(S D)$ \\
\hline Hours & 79 & $37.5(56.2)$ & 72 & $35.9(54.7)$ & 21 & $30.4(40.0)$ \\
\hline Weeks & 88 & $9.1(9.1)$ & 80 & $8.7(9.0)$ & 22 & $10.5(9.4)$ \\
\hline Hours/week & 78 & $4.0(4.0)$ & 70 & $3.9(3.8)$ & 21 & 4.1 (3.6) \\
\hline
\end{tabular}

the treatments described varied greatly. For instance, Hewitt, Evans, and Dritschel (2006) offered only 30 minutes of planning training, while in the study by Wertz et al. (1981) a group of veterans received 48 weeks of aphasia treatment with 8 hours of treatment each week ( 352 hours in total).

The total number of treatment hours was known for 79 studies (83\%); the number of weeks the treatment was offered was known for 88 studies $(93 \%)$, and the number of hours per week for 78 studies (82\%). Planned treatment was rarely the same as actual treatment delivered and both are shown in Table 3. The mean $(S D)$ actual number of hours treatment given was only reported in 21 studies where it was 30.4 (40.0) hours in total, equivalent to 4.0 (3.6) hours a week.

In 46 studies (48\%) treatment was offered individually, while in 8 studies $(8 \%)$ it was offered in groups. In some cases individual and group treatment was combined in one treatment programme $(n=7 ; 7 \%)$ and occasionally individual treatment and group treatment were compared in an experimental setting $(n=2 ; 2 \%)$ as in the study by Vanderploeg et al. (2008). Information on treatment form was not available for one third of the studies $(n=32)$.

In 18 studies the treatment was not restricted to therapy sessions, but homework was also arranged (19\%). Practising only at home without therapy sessions was studied in 5 cases (5\%). For instance, in the study by Kasten, Wust, Behrens-Baumann, and Sabel (1998) a computer was placed at the patient's home enabling daily practice. This kind of information was lacking in $75 \%$ of the studies $(n=71)$.

In 73 studies $(77 \%)$ there was no information available about the involvement of caregivers in the study or in treatment. In only four studies was the caregiver actually involved in therapy (4\%), while in 12 studies (13\%) the caregiver was involved in outcome measurements but not therapy. Occasionally the caregiver was asked to give informed consent, or was only involved in the control treatment $(n=5 ; 5 \%)$.

In Table 4 the setting in which treatment was offered is presented. This information was missing in 16 studies (17\%). In most cases patients were treated in the experimental setting of the study after being referred from a 
TABLE 4

Treatment setting

\begin{tabular}{lcr}
\hline Setting & $N$ & $\%$ \\
\hline Hospital/stroke unit & 20 & 21 \\
Laboratory/research centre/experimental setting & 19 & 20 \\
No information available & 16 & 17 \\
Multiple settings & 11 & 12 \\
Community/home & 7 & 7 \\
Rehabilitation centre (inpatient and outpatient combined) & 9 & 10 \\
Rehabilitation centre (inpatient) & 6 & 6 \\
Rehabilitation centre (outpatient) & 5 & 5 \\
Other & 2 & 2 \\
Total & 95 & 100 \\
\hline
\end{tabular}

hospital or outpatient clinic $(n=19 ; 20 \%)$. Patients in hospitals $(n=20$; $21 \%$ ) and rehabilitation centres (inpatient as well as outpatient programmes) were also studied frequently $(n=20$ in total; $21 \%)$.

In Table 5 the disciplines involved in treatment are presented. In 19 studies (20\%) the therapist was not specified and in 22 studies (23\%) information about the clinicians involved was not available at all. We could not find information about the necessary experience, knowledge or skills of the staff in any studies. Speech and language pathologists were most often specified $(n=12$; $13 \%$ ) and in $13 \%$ of the cases a computer with or without a therapist involved was used for treatment $(n=12)$.

Detailed information on stated treatment goals and outcome measures, and type of intervention can also be obtained from the authors. Treatment goals were not specified in 16 studies (18\%), while in many cases the goals for treatment were only specified very generally such as "to improve memory function". In some studies the treatment goals can be derived from the outcome measures that were used to evaluate the treatment effect. For instance, Antonucci et al. (1995) did not describe treatment goals explicitly, but the treatment effect was measured in terms of the presence of neglect disorders in daily life situations; one could derive from this information that the training was supposed to influence the level of activities. In many studies outcome measures on the level of impairments (i.e., neuropsychological tests) were combined with outcome measures at the level of activities. In only a few studies treatment was directed at participation and well-being (for instance, in the study of Lyon et al., 1997).

Intervention studies were designed differently in terms of the treatment to which the experimental treatment was compared. In most cases a control treatment was offered $(n=28 ; 30 \%)$ or the experimental treatment was compared to care as usual $(n=29 ; 31 \%)$. In 14 studies the control groups 
TABLE 5

Disciplines offering treatment

\begin{tabular}{lrr}
\hline Discipline & $N$ & $\%$ \\
\hline Clinician/therapist & 22 & 23 \\
No information available & 19 & 20 \\
Computer, in combination with therapist & 12 & 13 \\
Speech and language pathologist & 12 & 13 \\
Combinations of disciplines & 12 & 13 \\
Experimenter/researcher/examiner & 6 & 6 \\
Occupational therapist & 5 & 5 \\
Psychologist & 5 & 5 \\
Volunteer/student & 2 & 2 \\
Total & 95 & 100 \\
\hline
\end{tabular}

received no treatment (15\%) or two experimental treatments were compared $(n=11 ; 12 \%)$. In the remaining studies combinations of control treatments were offered $(n=13 ; 14 \%)$.

Where the content of the experimental treatment was described, the information was structured in many different ways, with no common headings or format. In 19 studies only the type of treatment was given without any detail about the content of treatment, for instance, "speech therapy" (Lincoln et al., 1984), while in other studies the content of treatment was presented in appendices in which the content per session was described, for instance, in the study of Man, Soong, Tam, and Hui-Chan (2006). In some studies a reference to a specific training is given and thus to be found in detail elsewhere; for instance, Dahlberg et al. (2007) refer to a workbook on group treatment for social skills.

Details about the control intervention were even less. In 34 studies only "control treatment" or "conventional treatment" was mentioned. In a few studies also a reference is given for a description of conventional therapy, for instance, in the study of Prins, Schoonen, and Vermeulen (1989). Additionally, in 19 studies there was no treatment given in the control group. A remarkable observation is that in many studies the outcome measures are all described in high detail while the intervention is only described in very general terms. A detailed description of the differences between control and experimental treatments was not available in any report, but where two experimental treatments were given, differences were sometimes tabulated.

\section{Effectiveness of treatment}

In more than half of the studies, the experimental treatment was more effective than the control treatment $(n=53)$, while in one quarter of the studies there was no difference between experimental and control treatment $(n=22)$. 
In the remaining studies $(n=17 ; 20 \%)$ the effects showed more variation (i.e., treatment altered function in some domains more than in others).

\section{DISCUSSION}

The evidence relating to the effects of cognitive rehabilitation has evolved rapidly since 2005: the Cicerone reviews included only 46 class I studies up to 2002 (review of 2000 included 29 class I studies, and in 2005 another 17 class I studies were included) (Cicerone et al., 2000; 2005) while we could include 95 class I studies up to 2010 representing 4068 patients in total. Just recently, a new update of the Cicerone review (Cicerone et al., 2011) was published in which another 19 class I studies were added. Our review has thus shown that many more randomised studies have been carried out, albeit the number of larger studies (100 patients or more) remains low at seven. Cicerone et al. concluded that 37 out of the 47 studies (79\%) showed a beneficial effect of cognitive rehabilitation. Cicerone et al. (2011) conclude in their latest update that there is now sufficient information to support evidence-based clinical protocols, and to design and implement empirically-supported treatments for cognitive disabilities after stroke and TBI, but is that really the case?

In our review in 22 out of 95 studies (23\%) there was no difference between the experimental treatment and control treatment and in another $20 \%$ the effects were partial (i.e., not on the primary or all outcome measures); making this distinction in treatment effectiveness, our conclusions are less promising. In this systematic review, the $95 \mathrm{RCTs}$ on the efficacy of rehabilitation for cognitive deficits have been analysed thoroughly and give the opportunity to build a detailed database on evidence-based cognitive rehabilitation which can be used by clinicians in selecting the current best evidence for treatment decisions and by researchers in formulating new research objectives. However, the review also shows that the treatments are only occasionally described in sufficient detail to allow replication of the study or use of the treatment clinically after reading the paper, and the control treatment is similarly hardly ever described. However in 54\% of studies, a statistically significant effect of the experimental treatment was shown, but even this positive conclusion is qualified by the small size of most studies - only seven studies included 100 or more patients and 39\% had less that 20 patients - and by the heterogeneity of the cognitive domains studied.

The details given concerning the treatment investigated should be set in the general context of the description of other healthcare interventions. The usual model used is that of a drug intervention, where the physical, pharmacological and other characteristics of the treatment are always carefully described and controlled. However in practice almost all other healthcare interventions, 
including surgery, behavioural therapy and rehabilitation therapies are poorly described, if described at all. In a semi-systematic review of non-pharmacological treatment trials, Glasziou, Meats, Heneghan, and Shepperd (2008) concluded that the clinician trying to replicate non-pharmacological treatments in practice hardly ever has sufficient detail about the "how to". Thus the findings in this review should not be surprising. Boutron et al. (2005) acknowledged the specific methodology of non-pharmacological trials and suggested an alternative checklist to report such trials.

There are several reasons for this state of affairs. First, there is no agreed framework for describing rehabilitation treatments (Wade, 2005) or indeed complex interventions. In the absence of a standardised way to describe an intervention many people simply do not attempt it. Second, researchers are likely to face great difficulties in publishing the intervention itself. Moreover, it will be especially difficult to publish a description of an intervention proven not to work, but this is of equal or greater importance. Thirdly, although the importance of complex interventions has been recognised, the standards applied to randomised studies do not require full description of the intervention. Even the CONSORT statement structured for complex interventions requires only one item saying "sufficient details to allow replication, including how and when they were actually administered" should be given in which the operationalisation of "sufficient details" is up to the author, and only one item in the registration of RCTs on clinicaltrial.gov concerns the treatment, and no guidance is given. Perera, Heneghan, and Yudkin (2007) proposed a graphical method for depicting RCTs of complex interventions which should support the comparison of interventions in the trial. This is a first step to a clearer description of non-drug treatments.

The difficulty of knowing what rehabilitation treatment is has been likened to a Russian doll (Whyte \& Hart, 2003), However, at least one suggestion has been made on how to improve the description of therapies (Wade, 2005) and some recently evaluated treatments have been published in detail (Winkens, Van Heugten, Wade, \& Fasotti, 2009). In addition, the American Congress of Rehabilitation Medicine just recently published the beta version of a "Cognitive rehabilitation manual" of which the authors state it provides step-by-step instructions for the interventions recommended in the Cicerone reviews (www.acrm.org/cognitive-rehabilitation-manual). The first edition of this manual, which is expected in the Spring of 2012, should show whether the lack of knowledge on the content of treatment from the journal articles reviewed here is indeed sufficiently covered.

Drawing general conclusions about "cognitive rehabilitation" is further complicated by the wide range of cognitive problems studied. We categorised outcomes into eight domains used by others, but the severity and complexity of problems faced by patients included varied considerably. Moreover the outcome measures used in cognitive rehabilitation studies are also often 
limited to the level of impairment, making it difficult to judge the clinical relevance and importance of any effect. The underlying disease also varies and, with this, it is likely that the associated impairments (cognitive and non-cognitive) vary greatly. Lastly the patients studied are usually young and quite selected, but most patients with cognitively based problems are old and have multiple problems. In contrast there are many more studies of physiotherapy; they tend to study only two domains, mobility and arm function, and they usually include more patients.

TABLE 6

Checklist for description of rehabilitation interventions

\begin{tabular}{|c|c|}
\hline Item & Aim \\
\hline Patient characteristics (input) & $\begin{array}{l}\text { Is my patient comparable to the patients in the } \\
\text { study? } \\
\text { - Age } \\
\text { - Gender } \\
\text { - Type of injury } \\
\text { - Time since injury } \\
\text { - Indications for treatment } \\
\text { - Contra-indications } \\
\text { - } \quad \ldots\end{array}$ \\
\hline $\begin{array}{l}\text { Intervention characteristics (process, structure, } \\
\text { context) }\end{array}$ & $\begin{array}{l}\text { What is the treatment? } \\
\text { - Activity: } \\
\text { - frequency, intensity, duration } \\
\text { - Individual or group } \\
\text { - involvement of caregivers/others } \\
\text { - direct or contextual treatment } \\
\text { Can I offer this intervention in my own setting? } \\
\text { - Context: } \\
\text { - organisation (healthcare setting) } \\
\text { - theoretical basis } \\
\text { - Necessary resources: } \\
\text { - physical (equipment) } \\
\text { - knowledge (of staff) } \\
\text { - skills (of staff) } \\
\text {-.... }\end{array}$ \\
\hline $\begin{array}{l}\text { Treatment goals and outcome (anticipated } \\
\text { outcome) }\end{array}$ & $\begin{array}{l}\text { What are the costs/benefits for my patient and his } \\
\text { family? } \\
\text { - Treatment goal (proximal, immediate) } \\
\text { - Treatment goal (distal, general) } \\
\text { - Expected effect size } \\
\text { - for patient } \\
\text { - for caregivers } \\
\text { - Differential effects for subgroups } \\
\text { - Adverse effects } \\
\text { - } \quad \ldots\end{array}$ \\
\hline
\end{tabular}


This review has its own limitations. It is quite possible that we failed to identify some RCTs, although in fact our strategy identified those found in other systematic reviews. It is possible that detailed descriptions of some interventions were published somewhere, but were not referred to in the original study. It is also possible that some studies had their own written protocols.

We decided that we would limit our attempts to find details to those (a) that most clinicians would make, and (b) that were most likely to succeed (because about half of all studies were undertaken over 10 years ago, making it unlikely that we would find the researcher or that they would still have the treatment protocol). We checked whether a reference to a treatment description was given but could not search systematically for descriptions, particularly if published after the main study. In searching we put ourselves in the position of a working neuropsychologist or other professional in following up a reference to an accessible journal.

Third, our data extraction obviously may have been weak in terms of the items extracted. However, none of the studies gave any additional details not included in the categories we used, and we feel that the information we searched for was a reasonable minimum.

The main implication of this review is that the evidence on cognitive rehabilitation is growing rapidly, but a clinician cannot pursue true "evidencebased" cognitive rehabilitation at present because there is insufficient published detail about the nature of any treatment that has been evaluated, and the evidence for effectiveness for any single treatment is not sufficient.

In future, studies need to give a clear description of the treatment offered both in the experimental group and in the control group. We would suggest that the characteristics shown in Table 6 would be a reasonable minimum. Such a checklist should ideally be considered by an international group, such as the CONSORT group or the Special Interest Group on Neuropsychological Rehabilitation (SIG-NR) of the World Federation for Neurorehabilitation (WFNR), making standardised description of interventions a fixed habit of transparent reporting of trials.

\section{REFERENCES}

Antonucci, G., Guariglia, C., Judica, A., Magnotti, L., Paolucci, S., Pizzamiglio, L., et al. (1995). Effectiveness of neglect rehabilitation in a randomized group study. Journal of Clinical and Experimental Neuropsychology, 17, 383-389.

Bakheit, A. M., Shaw, S., Barrett, L., Wood, J., Carrington, S., Griffiths, S., et al. (2007). A prospective, randomized, parallel group, controlled study of the effect of intensity of speech and language therapy on early recovery from poststroke aphasia. Clinical Rehabilitation, 21, $885-894$. 
Barker-Collo, S. L., Feigin, V. L., Lawes, C. M., Parag, V., Senior, H., \& Rodgers, A. (2009). Reducing attention deficits after stroke using attention process training: A randomized controlled trial. Stroke, 40, 3293-3298.

Berg, I. J., Koning-Haanstra, M., \& Deelman, B. G. (1991). Long-term effects of memory rehabilitation: A controlled study. Neuropsychological Rehabilitation, 1, 97-111.

Boutron, I., Moher, D., Tugwell, P., Giraudeau, B., Poiraudeau, S., Nizard, R., et al. (2005). A checklist to evaluate a report of a nonpharmacological trial (CLEAR NPT) was developed using consensus. Journal of Clinical Epidemiology, 58, 1233-1240.

Carter, L. T., Howard, B. E., \& O'Neil, W. A. (1983). Effectiveness of cognitive skill remediation in acute stroke patients. American Journal of Occupational Therapy, 37, 320-326.

Cheng, S. K. W., \& Man, D. W. K. (2006). Management of impaired self-awareness in persons with traumatic brain injury. Brain Injury, 20, 621-628.

Cherney, L. R., Halper, A. S., \& Papachronis, D. (2003). Two approaches to treating unilateral neglect after right hemisphere stroke: A preliminary investigation. Topics in Stroke Rehabilitation, 9, 22-33.

Cicerone, K. D., Dahlberg, C., Kalmar, K., Langenbahn, D. M., Malec, J. F., Bergquist, T. F., et al. (2000). Evidence-based cognitive rehabilitation: Recommendations for clinical practice. Archives of Physical Medicine and Rehabilitation, 81, 1596-1615.

Cicerone, K. D., Dahlberg, C., Malec, J. F., Langenbahn, D. M., Felicetti, T., Kneipp, S., et al. (2005). Evidence-based cognitive rehabilitation: Updated review of the literature from 1998 through 2002. Archives of Physical Medicine and Rehabilitation, 86, 1681-1692.

Cicerone, K. D., Langenbahn, D. M., Braden, C., Malec, J. F., Kalmar, K., Fraas, M., et al. (2011). Evidence-based cognitive rehabilitation: Updated review of the literature from 2003 through 2008. Archives of Physical Medicine and Rehabilitation, 92, 519-530.

Couillet, J., Soury, S., Lebornec, G., Asloun, S., Joseph, P. A., Mazaux, J. M., et al. (2010). Rehabilitation of divided attention after severe traumatic brain injury: A randomised trial. Neuropsychological Rehabilitation, 20, 321-339.

Dahlberg, C. A., Cusick, C. P., Hawley, L. A., Newman, J. K., Morey, C. E., Harrison-Felix, C. L., et al. (2007). Treatment efficacy of social communication skills training after traumatic brain injury: A randomized treatment and deferred treatment controlled trial. Archives of Physical Medicine and Rehabilitation, 88, 1561-1573.

David, R., Enderby, P., \& Bainton, D. (1982). Treatment of acquired aphasia: Speech therapists and volunteers compared. Journal of Neurology, Neurosurgery and Psychiatry, 45, 957-961.

Denes, G., Perazzolo, C., Piani, A., \& Piccione, F. (1996). Intensive versus regular speech therapy in global aphasia: A controlled study. Aphasiology, 10, 385-394.

Di Carlo, L. M. (1980). Language recovery in aphasia: Effect of systematic filmed programmed instruction. Archives of Physical Medicine and Rehabilitation, 61, 41-44.

Dirette, D. K., \& Hinojosa, J. (1999). The effects of a compensatory intervention on processing deficits of adults with acquired brain injuries. Occupational Therapy Journal of Research, 19, 223-240.

Dirette, D. K., Hinojosa, J., \& Carnevale, G. J. (1999). Comparison of remedial and compensatory interventions for adults with acquired brain injuries. Journal of Head Trauma Rehabilitation, 14, 595-601.

Doesborgh, S., van de Sandt-Koenderman, M., Dippel, D., van Harskamp, F., Koudstaal, P., \& Visch-Brink, E. (2004a). Cues on request: The efficacy of Multicue, a computer program for wordfinding therapy. Aphasiology, 18, 213-222.

Doesborgh, S. J., van de Sandt-Koenderman, M. W., Dippel, D. W., van Harskamp, F., Koudstaal, P. J., \& Visch-Brink, E. G. (2004b). Effects of semantic treatment on verbal communication and linguistic processing in aphasia after stroke: A randomized controlled trial. Stroke, 35, 141-146. 
Donkervoort, M., Dekker, J., Stehmann-Saris, F. C., \& Deelman, B. G. (2001). Efficacy of strategy training in left hemisphere stroke patients with apraxia: A randomised clinical trial. Neuropsychological Rehabilitation, 11, 549-566.

Doornhein, K., \& De Haan, E. H. F. (1998). Cognitive training for memory deficits in stroke patients. Neuropsychological Rehabilitation, 8, 393-400.

Dou, Z. L., Man, D. W., Ou, H. N., Zheng, J. L., \& Tam, S. F. (2006). Computerized errorless learning-based memory rehabilitation for Chinese patients with brain injury: A preliminary quasi-experimental clinical design study. Brain Injury, 20, 219-225.

Drummond, S. S., \& Rentschler, G. J. (1981). The efficacy of gestural cueing in dysphasic wordretrieval responses. Journal of Communication Disorders, 14, 287-298.

Edmans, J. A., Webster, J., \& Lincoln, N. B. (2000). A comparison of two approaches in the treatment of perceptual problems after stroke. Clinical Rehabilitation, 14, 230-243.

Elman, R. J., \& Bernstein-Ellis, E. (1999). The efficacy of group communication treatment in adults with chronic aphasia. Journal of Speech, Language, and Hearing Research, 42, 411-419.

Fanthome, Y., Lincoln, N. B., Drummond, A., \& Walker, M. F. (1995). The treatment of visual neglect using feedback of eye movements: A pilot study. Disability and Rehabilitation, 17, 413-417.

Fasotti, L., Kovacs, F., Eling, P. A. T. M., \& Brouwer, W. H. (2000). Time pressure management as a compensatory strategy training after closed head injury. Neuropsychological Rehabilitation, 10, 47-65.

Freeman, M. R., Mittenberg, W., Dicowden, M., \& Bat-Ami, M. (1992). Executive and compensatory memory retraining in traumatic brain injury. Brain Injury, 6, 65-70.

Geurtsen, G. J., van Heugten, C. M., Martina, J. D., \& Geurts, A. C. H. (2010). Comprehensive rehabilitation programmes in the chronic phase after severe brain injury: A systematic review. Journal of Rehabilitation Medicine, 42, 97-110.

Glasziou, P., Meats, E., Heneghan, C., \& Shepperd, S. (2008). What is missing from descriptions of treatment in trials and reviews? British Medical Journal, 336, 1472-1474.

Goverover, Y., Johnston, M. V., Toglia, J., \& Deluca, J. (2007). Treatment to improve selfawareness in persons with acquired brain injury. Brain Injury, 21, 913-923.

Gray, J. M., Robertson, I., Pentland, B., \& Anderson, S. (1992). Microcomputer-based attentional retraining after brain damage: A randomised group controlled trial. Neuropsychological Rehabilitation, 2, 97-115.

Hewitt, J., Evans, J. J., \& Dritschel, B. (2006). Theory driven rehabilitation of executive functioning: Improving planning skills in people with traumatic brain injury through the use of an autobiographical episodic memory cueing procedure. Neuropsychologia, $44,1468-1474$.

Hildebrandt, H., Bussmann-Mork, B., \& Schwendemann, G. (2006). Group therapy for memory impaired patients: A partial remediation is possible. Journal of Neurology, 253, 512-519.

Hinckley, J. J., Patterson, J. P., \& Carr, T. H. (2001). Differential effects of context- and skillbased treatment approaches: Preliminary findings. Aphasiology, 15, 463-476.

Jacquin-Courtois, S., Rode, G., Pavani, F., O’Shea, J., Giard, M. H., Boisson, D., et al. (2010). Effect of prism adaptation on left dichotic listening deficit in neglect patients: Glasses to hear better? Brain, 133, 895-908.

Kalra, L., Perez, I., Gupta, S., \& Wittink, M. (1997). The influence of visual neglect on stroke rehabilitation. Stroke, 28, 1386-1391.

Kaschel, R., Della Sala, S., Cantagallo, A., Fahlböck, A., Laaksonen, R., \& Kazen, M. (2002). Imagery mnemonics for the rehabilitation of memory: A randomised group controlled trial. Neuropsychological Rehabilitation, 12, 127-153.

Kasten, E., Wust, S., Behrens-Baumann, W., \& Sabel, B. A. (1998). Computer-based training for the treatment of partial blindness. Nature Medicine, 4, 1083-1087. 
Katz, N., Ring, H., Naveh, Y., Kizony, R., Feintuch, U., \& Weiss, P. L. (2005). Interactive virtual environment training for safe street crossing of right hemisphere stroke patients with Unilateral Spatial Neglect. Disability and Rehabilitation, 27, 1235-1243.

Katz, R. C., \& Wertz, R. T. (1997). The efficacy of computer-provided reading treatment for chronic aphasic adults. Journal of Speech, Language, and Hearing Research, 40, 493-507.

Kerner, M. J., \& Acker, M. (1985). Computer delivery of memory retraining with head injured patients. Cognitive Rehabilitation, 3, 26-31.

Levine, B., Robertson, I. H., Clare, L., Carter, G., Hong, J., Wilson, B. A., et al. (2000). Rehabilitation of executive functioning: An experimental-clinical validation of Goal Management Training. Journal of the International Neuropsychological Society, 6, 299-312.

Lincoln, N. B., McGuirk, E., Mulley, G. P., Lendrem, W., Jones, A. C., \& Mitchell, J. R. (1984). Effectiveness of speech therapy for aphasic stroke patients. A randomised controlled trial. Lancet, 1, 1197-1200.

Lincoln, N. B., \& Pickersgill, M. J. (1984). The effectiveness of programmed instruction with operant training in the language rehabilitation of severely aphasic patients. Behavioural Psychotherapy, 12, 237-248.

Lincoln, N. B., Pickersgill, M. J., Hankey, A. I., \& Hilton, C. R. (1982). An evaluation of operant training and speech therapy in the language rehabilitation of moderate aphasics. $B e$ havioural Psychotherapy, 10, 162-178.

Lincoln, N. B., Whiting, S. E., Cockburn, J., \& Bhavnani, G. (1985). An evaluation of perceptual retraining. International Rehabilitation Medicine, 7, 99-101.

Luukkainen-Markkula, R., Tarkka, I. M., Pitkänen, K., Sivenius, J., \& Hämäläinen, H. (2009). Rehabilitation of hemispatial neglect: A randomized study using either arm activation or visual scanning training. Restorative Neurology and Neuroscience, 27, 663-672.

Lyon, J. G., Cariski, D., Keisler, L., Rosenbek, J., Levine, R., Kumpula, J., et al. (1997). Communication partners: Enhancing participation in life and communication for adults with aphasia in natural settings. Aphasiology, 11, 693-708.

MacKay, S., Holmes, D. W., \& Gersumky, A. T. (1988). Methods to assess aphasic stroke patients. Geriatric Nursing, 9, 177-179.

Malec, J., Jones, R., Rao, N., \& Stubbs, K. (1984). Video game practice effects on sustained attention in patients with craniocerebral trauma. Cognitive Rehabilitation, 2, 18-23.

Man, D. W., Soong, W. Y., Tam, S. F., \& Hui-Chan, C. W. (2006). A randomized clinical trial study on the effectiveness of a tele-analogy-based problem-solving programme for people with acquired brain injury (ABI). NeuroRehabilitation, 21, 205-217.

Mazer, B. L., Sofer, S., Korner-Bitensky, N., Gelinas, I., Hanley, J., \& Wood-Dauphinee, S. (2003). Effectiveness of a visual attention retraining program on the driving performance of clients with stroke. Archives of Physical Medicine and Rehabilitation, 84, 541-550.

McPherson, K. M., Kayes, N., \& Weatherall, M. (2009). A pilot study of self-regulation informed goal setting in people with traumatic brain injury. Clinical Rehabilitation, 23, 296-309.

Meikle, M., Wechsler, E., Tupper, A., Benenson, M., Butler, J., Mulhall, D., et al. (1979). Comparative trial of volunteer and professional treatments of dysphasia after stroke. British Medical Journal, 2, 87-89.

Meinzer, M., Streiftau, S., \& Rockstroh, B. (2007). Intensive language training in the rehabilitation of chronic aphasia: Efficient training by laypersons. Reviews, 13, 846-853.

Neistadt, M. E. (1992). Occupational therapy treatments for constructional deficits. American Journal of Occupational Therapy, 46, 141-148.

Niemann, H., Ruff, R. M., \& Baser, C. A. (1990). Computer-assisted attention retraining in head-injured individuals: A controlled efficacy study of an outpatient program. Journal of Consulting and Clinical Psychology, 58, 811-817. 
Novack, T. A., Caldwell, S. G., Duke, L. W., Bergquist, T. F., \& Gage, R. J. (1996). Focused versus unstructured intervention for attention deficits after traumatic brain injury. Journal of Head Trauma Rehabilitation, 11, 52-60.

Ownsworth, T. L., \& McFarland, K. (1999). Memory remediation in long-term acquired brain injury: Two approaches in diary training. Brain Injury, 13, 605-626.

Perera, R., Heneghan, C., \& Yudkin, P. (2007). Graphical method for depicting randomised trials of complex interventions. British Medical Journal, 334, 127-129.

Poggel, D. A., Kasten, E., \& Sabel, B. A. (2004). Attentional cueing improves vision restoration therapy in patients with visual field defects. Neurology, 63, 2069-2076.

Prins, R. S., Schoonen, R., \& Vermeulen, J. (1989). Efficacy of two different types of speech therapy for aphasic stroke patients. Applied Psycholinguistics, 10, 85-123.

Pulvermuller, F., Neininger, B., Elbert, T., Mohr, B., Rockstroh, B., Koebbel, P., et al. (2001). Constraint-induced therapy of chronic aphasia after stroke. Stroke, 32, 1621-1626.

Robertson, I. H., McMillan, T. M., MacLeod, E., Edgeworth, J., \& Brock, D. (2002). Rehabilitation by limb activation training reduces left-side motor impairment in unilateral neglect patients: A single-blind randomised control trial. Neuropsychological Rehabilitation, 12, 439-454.

Rochon, E., Laird, L., Bose, A., \& Scofield, J. (2005). Mapping therapy for sentence production impairments in nonfluent aphasia. Neuropsychological Rehabilitation, 15, 1-36.

Rohling, M. L., Faust, M. E., Beverly, B., \& Demakis, G. (2009). Effectiveness of cognitive rehabilitation following acquired brain injury: A meta-analytic re-examination of Cicerone et al.'s $(2000,2005)$ systematic reviews. Neuropsychology, 23, 20-39.

Rose, F. D., Brooks, B. M., Attree, E. A., Parslow, D. M., Leadbetter, A. G., McNeil, J. E., et al. (1999). A preliminary investigation into the use of virtual environments in memory retraining after vascular brain injury: Indications for future strategy? Disability and Rehabilitation, 21, 548-554.

Rossi, P. W., Kheyfets, S., \& Reding, M. J. (1990). Fresnel prisms improve visual perception in stroke patients with homonymous hemianopia or unilateral visual neglect. Neurology, 40, $1597-1599$.

Ruff, R., Mahaffey, R., Engel, J., Farrow, C., Cox, D., \& Karzmark, P. (1994). Efficacy study of THINKable in the attention and memory retraining of traumatically head-injured patients. Brain Injury, 8, 3-14.

Rusconi, M. L., Meinecke, C., Sbrissa, P., \& Bernardini, B. (2002). Different cognitive trainings in the rehabilitation of visuo-spatial neglect. Europa Medicophysica, 38, 159-166.

Ryan, T. V., \& Ruff, R. M. (1988). The efficacy of structured memory retraining in a group comparison of head trauma patients. Archives of Clinical Neuropsychology, 3, 165-179.

Salazar, A. M., Warden, D. L., Schwab, K., Spector, J., Braverman, S., Walter, J., et al. (2000). Cognitive rehabilitation for traumatic brain injury: A randomized trial. Journal of the American Medical Association, 283, 3075-3081.

Sarkamo, T., Tervaniemi, M., Laitinen, S., Forsblom, A., Soinila, S., Mikkonen, M., et al. (2008). Music listening enhances cognitive recovery and mood after middle cerebral artery stroke. Brain, 131, 866-876.

Schmitter-Edgecombe, M., Fahy, J. F., Whelan, J. P., \& Long, C. J. (1995). Memory remediation after severe closed head injury: Notebook training versus supportive therapy. Journal of Consulting and Clinical Psychology, 63, 484-489.

Shewan, C. M., \& Kertesz, A. (1984). Effects of speech and language treatment on recovery from aphasia. Brain and Language, 23, 272-299.

Si Hyun, K., Kim, D. K., Kyung Mook, S., Kwang Nam, C., Jin Yong, Y., Sang Yoon, S., et al. (2009). A computerized visual perception rehabilitation programme with interactive computer interface using motion tracking technology - a randomized controlled, single-blinded, pilot clinical trial study. Clinical Rehabilitation, 23, 434-444. 
Smania, N., Aglioti, S. M., Girardi, F., Tinazzi, M., Fiaschi, A., Cosentino, A., et al. (2006). Rehabilitation of limb apraxia improves daily life activities in patients with stroke. Neurology, 67, 2050-2052.

Smania, N., Girardi, F., Domenicali, C., Lora, E., \& Aglioti, S. (2000). The rehabilitation of limb apraxia: A study in left-brain-damaged patients. Archives of Physical Medicine and Rehabilitation, 81, 379-388.

Soderback, I. (1988). The effectiveness of training intellectual functions in adults with acquired brain damage. An evaluation of occupational therapy methods. Scandinavian Journal of Rehabilitation Medicine, 20, 47-56.

Sohlberg, M. M., McLaughlin, K. A., Pavese, A., Heidrich, A., \& Posner, M. I. (2000). Evaluation of attention process training and brain injury education in persons with acquired brain injury. Journal of Clinical and Experimental Neuropsychology, 22, 656-676.

Soong, W., Tam, S. F., Man, W. K., \& Hui-Chan, C. (2005). A pilot study on the effectiveness of tele-analogy-based problem-solving training for people with brain injuries. International Journal of Rehabilitation Research, 28, 341-347.

Spikman, J. M., Boelen, D. H., Lamberts, K. F., Brouwer, W. H., \& Fasotti, L. (2010). Effects of a multifaceted treatment program for executive dysfunction after acquired brain injury on indications of executive functioning in daily life. Journal of the International Neuropsychological Society, 16, 118-129.

Sturm, W., \& Willmes, K. (1991). Efficacy of a reaction training on various attentional and cognitive functions in stroke patients. Neuropsychological Rehabilitation, 1, 259-280.

Taylor, M. M., Schaeffer, J. N., Blumenthal, F. S., \& Grisell, J. L. (1971). Perceptual training in patients with left hemiplegia. Archives of Physical Medicine and Rehabilitation, 52, 163-169.

Thickpenny-Davis, K. L., \& Barker-Collo, S. L. (2007). Evaluation of a structured group format memory rehabilitation program for adults following brain injury. Journal of Head Trauma Rehabilitation, 22, 303-313.

Thomas-Stonell, N., Johnson, P., Schuller, R., \& Jutai, J. (1994). Evaluation of a computerbased program for remediation of cognitive-communication skills. Journal of Head Trauma Rehabilitation, 9, 25-37.

Tiersky, L. A., Anselmi, V., Johnston, M. V., Kurtyka, J., Roosen, E., Schwartz, T., et al. (2005). A trial of neuropsychologic rehabilitation in mild-spectrum traumatic brain injury. Archives of Physical Medicine and Rehabilitation, 86, 1565-1574.

Tsang, M. H., Sze, K. H., \& Fong, K. N. (2009). Occupational therapy treatment with right halffield eye-patching for patients with subacute stroke and unilateral neglect: A randomised controlled trial. Disability and Rehabilitation, 31, 630-637.

Twum, M., \& Parente, R. (1994). Role of imagery and verbal labeling in the performance of paired associates tasks by persons with closed head injury. Journal of Clinical and Experimental Neuropsychology, 16, 630-639.

van Hout, M. S. E., Wekking, E. M., Berg, I. J., \& Deelman, B. G. (2008). Psychosocial and cognitive rehabilitation of patients with solvent-induced chronic toxic encephalopathy: A randomised controlled study. Psychotherapy and Psychosomatics, 77, 289-297.

Vanderploeg, R. D., Schwab, K., Walker, W. C., Fraser, J. A., Sigford, B. J., Date, E. S., et al. (2008). Rehabilitation of traumatic brain injury in active duty military personnel and veterans: Defense and Veterans Brain Injury Center randomized controlled trial of two rehabilitation approaches. Archives of Physical Medicine and Rehabilitation, 89, 2227-2238.

Wade, D. T. (2005). Describing rehabilitation interventions. Clinical Rehabilitation, 19, 811-818.

Watanabe, T. K., Black, K. L., Zafonte, R. D., Millis, S. R., \& Mann, N. R. (1998). Do calendars enhance posttraumatic temporal orientation?: A pilot study. Brain Injury, 12, 81-85. 
Weinberg, J., Diller, L., Gordon, W. A., Gerstman, L. J., Lieberman, A., Lakin, P., et al. (1977). Visual scanning training effect on reading-related tasks in acquired right brain damage. Archives of Physical Medicine and Rehabilitation, 58, 479-486.

Weinberg, J., Diller, L., Gordon, W. A., Gerstman, L. J., Lieberman, A., Lakin, P., et al. (1979). Training sensory awareness and spatial organization in people with right brain damage. Archives of Physical Medicine and Rehabilitation, 60, 491-496.

Weinberg, J., Piasetsky, E., Diller, L., \& Gordon, W. (1982). Treating perceptual organization deficits in nonneglecting RBD stroke patients. Journal of Clinical Neuropsychology, 4, $59-75$

Wertz, R. T., Collins, M. J., Weiss, D., Kurtzke, J. F., Friden, T., Brookshire, R. H., et al. (1981). Veterans Administration cooperative study on aphasia: A comparison of individual and group treatment. Journal of Speech and Hearing Research, 24, 580-594.

Wertz, R. T., Weiss, D. G., Aten, J. L., \& Brookshire, R. H. (1986). Comparison of clinic, home, and deferred language treatment for aphasia: A Veterans Administration cooperative study. Archives of Neurology, 43, 653-658.

Westerberg, H., Jacobaeus, H., Hirvikoski, T., Clevberger, P., Ostensson, M. L., Bartfai, A., et al. (2007). Computerized working memory training after stroke - a pilot study. Brain Injury, 21, 21-29.

Whyte, J., \& Hart, T. (2003). It's more than a black box; it's a Russian doll: Defining rehabilitation treatments. American Journal of Physical Medicine and Rehabilitation, 82, 639-652.

Wiart, L., Come, A. B., Debelleix, X., Petit, H., Joseph, P. A., Mazaux, J. M., et al. (1997). Unilateral neglect syndrome rehabilitation by trunk rotation and scanning training. Archives of Physical Medicine and Rehabilitation, 78, 424-429.

Winkens, I., Van Heugten, C. M., Wade, D. T., \& Fasotti, L. (2009). Training patients in Time Pressure Management, a cognitive strategy for mental slowness. Clinical Rehabilitation, 23, 79-90.

Winkens, I., Van Heugten, C. M., Wade, D. T., Habets, E. J., \& Fasotti, L. (2009). Efficacy of time pressure management in stroke patients with slowed information processing: A randomized controlled trial. Archives of Physical Medicine and Rehabilitation, 90, 1672-1679.

Worrall, L., \& Yiu, E. (2000). Effectiveness of functional communication therapy by volunteers for people with aphasia following stroke. Aphasiology, 14, 911-924.

Zeloni, G., Farnè, A., \& Baccini, M. (2002). Viewing less to see better. Journal of Neurology, Neurosurgery and Psychiatry, 73, 195-198.

Manuscript received October 2011

Revised manuscript received March 2012

First published online April 2012 